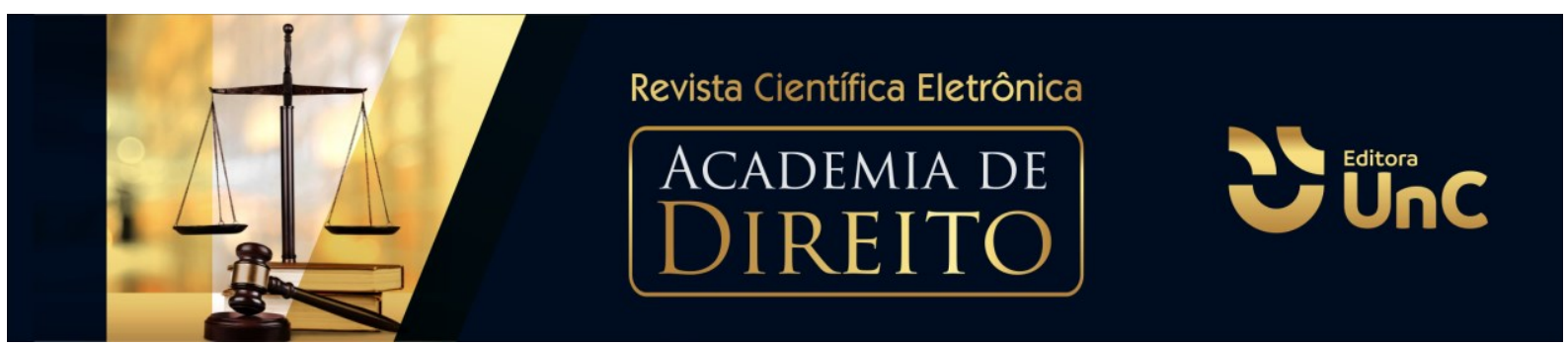

\title{
A NECESSIDADE DE TUTELA ESPECÍFICA AOS DIREITOS DOS ANIMAIS DOMÉSTICOS
}

\section{THE NEED FOR SPECIFIC PROTECTION TO THE RIGHTS OF DOMESTIC}

\section{ANIMALS}

\author{
Valléria Ritzmann Ribas ${ }^{1}$ \\ Elizeu Luiz Toporoski²
}

\begin{abstract}
RESUMO
O presente artigo discute os aspectos mais relevantes acerca da inclusão dos animais domésticos nos núcleos familiares e da possibilidade de guarda compartilhada, em casos de separação de casais. Registra-se a inexistência de Legislação Federal específica acerca dos casos em comento. É necessário, portanto, o estudo das relações sociais dos animais que vivem em âmbito familiar e que formam um novo conceito de família, a multiespécie, para amparar a respectiva normatização. $O$ problema aventado consiste na análise histórica da função dos animais domésticos, sua atual forma de inserção nas famílias e como isso têm ocasionado mudanças na vida das pessoas. Importante destacar que o animal não deve ser tratado como um mero objeto, mas como ser senciente. A metodologia consiste na análise da Constituição Federal e das lições doutrinárias e jurisprudenciais, além da utilização dos métodos indutivo, dedutivo e comparativo. Considerada a relevância do assunto, é essencial a provocação da atividade legislativa para delinear a vivência dos animais domésticos nos núcleos familiares, conferindo não apenas direitos, mas alento, a todos os envolvidos nestas novas relações de amor
\end{abstract}

Palavras-Chave: Animais Domésticos. Família. Guarda. Convivência.

\footnotetext{
${ }^{1}$ Graduanda de Direito. Universidade do Contestado (UnC). Campus Mafra. Santa Catarina. Brasil. Email: valleriaritzmann@hotmail.com

${ }^{2}$ Graduado em Direito pela Pontifícia Universidade Católica do Paraná. Pós-Graduação (especialização) em Direito Público pela Escola da Magistratura Federal do Paraná/Faculdades Integradas do Brasil. Mestre em Direito pelo Programa de Mestrado em Direitos Fundamentais e Democracia pelo Centro Universitário Unibrasil. Docente da Universidade do Contestado (UnC). Campus Mafra. Santa Catarina. Brasil. E-mail: elizeu.toporoski@gmail.com
} 


\begin{abstract}
This article argues the most relevant aspects about the inclusion of domestic animals in family nuclei and the possibility of shared custody, in cases of separation of couples. There is no specific Federal Legislation regarding the cases under review. Therefore, it is necessary to study the social relationships of animals that live in familiar environments and form a new concept of family, a multispecie, to support a specific standardization. The problem adventurous consists in a historical analysis of the function of domestic animals, their current form of insertion in families and how this has caused changes in people's lives. It is important to highlight that the animal should not be treated as a mere object, but as a sentient being. The methodology consists of analyzing the Federal Constitution and the doctrinal and jurisprudential lessons, in addition to using the inductive, deductive and comparative methods. Considering the relevance of the subject, it is essential to provoke legislative activity to outline the experience of domestic animals in family nuclei, conferring not only rights, but encouragement, to everyone involved in these new love relationships.
\end{abstract}

Keywords: Domestic animals. Family. Guard. Coexistence.

\title{
1 INTRODUÇÃO
}

Levando em consideração as alterações da família e a relação entre os seres humanos com os objetos jurídicos, é de grande importância uma análise especial acerca da relação jurídica aplicável entre os animais e os seres humanos, responsáveis por sua tutela, bem como os aspectos da guarda compartilhada destes animais domésticos que integram o núcleo familiar.

Para o direito brasileiro, os animais ainda são vistos como um bem que existe para, de algum modo, suprir as necessidades humanas, sejam elas em questões alimentícias, econômicas ou domésticas. Apesar de o animal ainda ser visto como objeto para servir o homem, a sociedade apresentou grande avanço nas relações familiares, incluindo animais de estimação em seus lares.

Desse modo, o animal foi inserido como parte da família, criando vínculos com seus donos, sendo comum em processos de separação de casais que ao longo do relacionamento adquirem um animal para conviver, passam a ser afetados, pois, não existe nenhum amparo jurídico para solucionar a guarda do animal.

Verifica-se que ainda não há uma legislação específica para a proteção da tutela dos animais domésticos. Em alguns casos, a referida tutela é resolvida com 
aplicação analógica do Código Civil e dos artigos que dispõe sobre a guarda compartilhada.

Como mencionado acima, não há, ainda, uma Lei específica visando a proteção destes direitos. Contudo, já existe um Projeto de Lei 27/2018 aprovado pelo Senado Federal, "que acrescenta dispositivo à Lei n 9.605, de 12 de fevereiro de 1998 para dispor sobre a natureza jurídica dos animais não humano".

O objetivo do referido Projeto de Lei é criar um regime jurídico com a finalidade de amparar os direitos dos animais domésticos na esfera judicial, bem como alterar a forma como são tratados perante a legislação atual. Com a alteração, os animais passam a ser classificados como seres sencientes, ou seja, capazes de sentir, ter consciência e percepções.

Com a alteração da legislação, os animais não serão mais tratados como coisas, mas sim, como seres de Direito, integrando as Varas da Família para dirimir conflitos judiciais.

O Código Civil não traz nenhuma garantia de como serão divididos os custos para a manutenção e o direito de convivência com cada uma das partes nos casos de litígio entre os tutores do animal. Nestes casos, os tribunais apenas fazem alusão ao Código Civil por não existir opção viável e positivada para a resolução do conflito. $O$ conceito de família redigido no texto constitucional, fez com que seja possível o enquadramento da família multiespécie.

A Constituição Federal de 1988, em seu artigo 225, $\S 1^{\circ}$, inciso VII, garante a proteção jurídica aos animais, declarando que:

Todos têm direito ao meio ambiente ecologicamente equilibrado, bem de uso comum do povo e essencial à sadia qualidade de vida, impondo-se ao poder público e à coletividade o dever de defendê-lo e preservá-lo para as presentes e futuras gerações (BRASIL, 1988).

A finalidade do presente artigo se baseia na premissa de analisar a relação jurídica entre os animais domésticos e o ser humano, bem como verificar e estudar o embasamento das decisões proferidas nesta esfera, considerando que os animais domésticos merecem ter seus direitos garantidos com uma Lei específica.

Ademais, busca-se pluralizar o conceito de família, tendo em pauta o vínculo que ao longo do tempo são construídos entre homens e animais e que, como 
pertencentes ao núcleo familiar, não podem ser tratados como objeto, mas sim como sujeitos de direito que merecem garantias e tutela jurídica em Lei específica.

Em primeiro momento, o presente artigo abordará os animais domésticos sob os olhos da doutrina jurídica do Direito Pátrio trazendo doutrinas que os seleciona como seres detentores de Direitos abordando a importância da Constituição Federal para ampliar novos horizontes sobre este assunto.

Em seguida será debatido a importância das famílias multiespécie que de certa forma são novas perante a sociedade, mas muito comuns em todo o mundo. Também sobre a importância que os seres humanos dão aos animais, incluindo-os como entes da família.

Por fim, a problemática irá analisar algumas jurisprudências baseadas em fatos reais familiares incluindo animais e seres humanos pois, cada vez mais é corriqueiro os processos que envolvem animais de estimação.

\section{OS ANIMAIS COMO BENS NA DOUTRINA JURÍDICA DO DIREITO PÁTRIO}

A Legislação Brasileira considera os animais como "coisas", submete-os ao regime Civil de propriedade semovente, equiparando-os, assim, aos outros objetos sem vida, conforme o artigo 82 conceitua sobre os bens móveis, art. 936 ensina acerca da responsabilidade civil sobre o dano causado pelo animal e o art. 1.263 sobre a aquisição da propriedade, coisa sem dono (BRASIL, 2002).

Contudo, há uma grande contradição entre o direito patrimonial do Código Civil acerca da natureza jurídica dos animais e a Constituição Federal de 1988 que, em seu artigo 225, caput, dispõe que:

Todos têm direito ao meio ambiente ecologicamente equilibrado, bem de uso comum do povo e essencial à sadia qualidade de vida, impondo-se ao poder público e à coletividade o dever de defendê-lo e preservá-lo para as presentes e futuras gerações (BRASIL, 1988).

Sendo assim, a fauna deveria ser um elemento protegido pelo poder Público e por todos os seres humanos, já que é um interesse da coletividade. É necessário classificar todo o meio ambiente como um Direito Difuso, para que não seja 
considerado apenas como direito de propriedade, de exploração e utilização do ser humano (FERREIRA, 2014).

Verifica-se que o Direito dos Animais surgiu com a Constituição Federal de 1988, visto que foi neste regramento que a crueldade dos animais foi proibida, reconhecendo a dignidade e, principalmente, o Direito fundamental dos animais. É importante salientar que antes da Constituição Federal de 1988, nenhuma outra tratou sobre a questão dos animais (ATAIDE JUNIOR, 2018).

Ainda no artigo 225 da Constituição Federal de 1988, em seu inciso VII do $\S 1^{\circ}$, está previsto que qualquer prática de crueldade contra a fauna constitui crime, ou seja, a regra de proibição da crueldade animal está diretamente ligada a senciência dos animais e sua capacidade de percepção (BRASIL, 1988).

Neste contexto, se fala da fauna de forma geral, eis que, para o Direito dos animais, todos importam, tanto domésticos quanto silvestres, independente da sua influência ecológica, mas sim por conta de sua individualidade (BRASIL, 1988).

A questão em pauta é, especificamente, a violação dos direitos dos animais quando estes não são o reconhecido como um sujeito de Direito na legislação vigente (ATAIDE JÚNIOR, 2018).

É de suma importância destacar a classificação feita pela Portaria 93/98 do IBAMA (Instituto Brasileiro do Meio Ambiente e dos Recursos Naturais Renováveis) em seu artigo $2^{\circ}$, no qual divide a fauna em três categorias lecionadas, são elas:

\begin{abstract}
Fauna silvestre brasileira, são todos aqueles animais pertencentes às espécies nativas, migratórias e quaisquer outras, aquáticas ou terrestres, que tenham seu ciclo de vida ocorrendo dentro dos limites do Território Brasileiro ou águas jurisdicionais brasileiras. Fauna silvestre exótica, são todos aqueles animais pertencentes às espécies ou subespécies cuja distribuição geográfica não inclui o Território Brasileiro e as espécies ou subespécies introduzidas pelo homem, inclusive domésticas em estado asselvajado ou alçado. Também são consideradas exóticas as espécies ou subespécies que tenham sido introduzidas fora das fronteiras brasileiras e suas águas jurisdicionais e que tenham entrado em Território Brasileiro, e por fim, fauna doméstica, todos aqueles animais que através de processos tradicionais e sistematizados de manejo e/ou melhoramento zootécnico tornaram-se domésticas, apresentando características biológicas e comportamentais em estreita dependência do homem, podendo apresentar fenótipo variável, diferente da espécie silvestre que os originou (IBAMA, 1998).
\end{abstract}

Por fim, salienta-se que a Constituição é a estrutura de todo o Ordenamento Jurídico Brasileiro e que orienta as demais normas aplicáveis em nosso âmbito 
jurídico, sendo base para imperar as demais normas sobre aquelas que a contrariam (FERREIRA, 2014).

É evidente a existência de um conflito normativo entre a Constituição Federal, esta que classifica a fauna como um elemento do meio ambiente e um Direito Difuso; e o Código Civil, que categoriza os animais como bens, regulamentados pelos direitos de propriedade (FERREIRA, 2014).

De acordo com o artigo 225 da Constituição Federal de 1988, o meio ambiente é considerado um bem de uso comum do povo, ou seja, difuso. Ele é imaterial, indivisível, inapropriável e inalienável, não pode ser apropriado pelo Estado ou por particular, dessa forma, o Direito Transgeracional é um princípio incluído na Conferência das Nações Unidas sobre o Meio Ambiente realizado no ano de 1972 em Estocolmo, vislumbrando a proteção do meio ambiente, onde toda a coletividade precisa buscar um meio ambiente ecologicamente equilibrado e sadio para agora e para as futuras gerações. As ações humanas devem sempre buscar um meio ambiente equilibrado e o bem-estar social e coletivo (TRENNEPOHL, 2019).

Nesta perspectiva, deve-se analisar, a Declaração Universal dos Direitos dos Animais, inicialmente criada pela UNESCO, que, em seu artigo $2^{\circ}$, prevê que "cada animal tem direito e respeito". Ainda, em seu artigo $14^{\circ}$, a referida Declaração prevê que "os organismos de proteção e de salvaguarda dos animais devem estar representados a nível governamental". Sendo assim, esses direitos devem ser protegidos por Leis como os direitos humanos (UNESCO, 1978).

Portanto, o homem, que é classificado como uma espécie, não pode exterminar ou explorar os animais (AGUIAR, 2018).

Coadunado a isso, verifica-se que a ciência e a tecnologia têm apresentado grandes avanço sobre a senciência dos animais. Diariamente surgem novos índices de comprovações de que os animais são seres capazes de sentir, sofrer e ter consciência de sua própria existência (AGUIAR, 2018).

Neste ponto, vale ressaltar a importância da Declaração de Cambridge sobre a Consciência, esta que surgiu após anos de aprofundado estudo de um grupo de neurocientistas. O estudo concluiu que o homem não é o único animal com as estruturas neurológicas que geram consciência. 
Nós declaramos o seguinte: A ausência de um neocórtex não parece impedir que um organismo experimente estados afetivos. Evidências convergentes indicam que os animais não humanos têm os substratos neuroanatômicos, neuroquímicos e neurofisiológicos de estados de consciência juntamente como a capacidade de exibir comportamentos intencionais. Consequentemente, o peso das evidências indica que os humanos não são os únicos a possuir os substratos neurológicos que geram a consciência. Animais não humanos, incluindo todos os mamíferos e as aves, e muitas outras criaturas, incluindo polvos, também possuem esses substratos neurológicos ${ }^{3}$ (LOW et al., 2012).

Posto isto, verifica-se que os animais possuem todas as percepções e sentidos de um ser humano e, desse modo, impossível é a sua classificação como seres móveis/semoventes (AGUIAR, 2018).

Nesse sentido, o questionamento é: todos os animais são seres sencientes? Não são todos os animais que possuem esta habilidade sensorial e, de fato, é difícil categorizá-los. Entretanto, verifica-se que os animais domésticos (gatos, cachorros e até mesmo algumas espécies de peixes), em sua maioria, são sencientes, ou seja, são capazes de ter experiências mentais Vale lembrar também que um ser senciente não significa exatamente que é um ser vivo pois, nem tudo que está vivo possuí sentimentos, como as plantas, que são vivas, mas não sentem dor (FRANCIONE, 2015).

Destarte, é evidente que cada espécie é capaz de sentir e agir de formas diferentes. Em vista disto, as reformas jurídicas e processuais necessitam ser reconhecidas para readequar o ordenamento jurídico aos costumes e hábitos da sociedade atual.

\section{OS NOVOS CONCEITOS DE FAMÍLIAS MULTIESPÉCIE E A FALTA DE LEGISLAÇÃO ESPECÍFICA}

$\mathrm{O}$ animal antigamente era visto apenas como um objeto que existia para, de algum modo, suprir as necessidades humanas, seja elas na questão alimentícia,

\footnotetext{
${ }^{3}$ A Declaração sobre a Consciência de Cambridge foi redigida por Philip Low e editada por Jaak Panksepp, Diana Reiss, David Edelman, Bruno Van Swinderen, Philip Low e Christof Koch. A Declaração foi anunciada publicamente em Cambridge, Reino Unido, em 7 de julho de 2012, na Conferência sobre a Consciência em Animais Humanos e não Humanos em memória a Francis Crick, realizada no Churchill College da Universidade de Cambridge, por Low, Edelman e Koch. A Declaração foi assinada por todas as pessoas participantes da conferência, naquela mesma noite, na presença de Stephen Hawking, no Salão Balfour do Hotel du Vin, em Cambridge, Reino Unido. A cerimônia de assinatura foi filmada para a posteridade pela CBS 60 Minutes.
} 
econômica ou doméstica. Apesar de ainda o animal ser visto como objeto para servir o homem, a sociedade apresentou grande avanço nas relações sócio afetivas incluindo animais de estimação em seus lares (FERREIRA, 2014).

A vida corrida das pessoas e a falta de tempo afastou a ideia de que a família é apenas formada por humanos, também muitas pessoas optam por ter animais em seus lares por problemas de fertilidade e deste modo adquirem um animal com intuito de suprir muitas vezes a falta que uma criança possa fazer, tornando as famílias brasileiras multiespécie (FERREIRA, 2014).

Os animais de estimação ganham cada vez mais espaço para integrar os lares brasileiros ganhando postos de entes queridos. A sociedade vem sendo influenciada por inúmeros fatores quando se escolhe um animal para conviver, criando fortes laços afetivos e considerando-os como entes detentores de Direitos. Com as alterações dos padrões de vida em sociedade, podemos classificar as famílias formadas por humanos e seus animais como multiespécie (VIEGAS; RABELO; PAMPLONA FILHO, 2020).

No Brasil, o Instituto Pet atualiza dados sobre a população de animais de estimação em todo o território nacional. No ano de 2018 foram contabilizados no país 54,2 milhões de cães, 39,8 milhões de aves, 23,9 milhões de gatos, 19,1 milhões de peixes e 2,3 milhões de répteis e pequenos mamíferos, a contabilização chega aos 139,3 milhões de animais. Os últimos dados coletados pelo IBGE no ano de 2013, foram cerca de 132,4 milhões de animais de estimação. É relevante o destaque para o gradual aumento de famílias que buscam um animal de estimação para conviver (INSTITUTO PET BRASIL, 2019).

Da leitura do texto do Código Civil de 1916, verifica-se que, naquela época, não era tão comum o afeto entre homem e animal e, por este motivo, poucos se preocupavam com a saúde, bem-estar e com a guarda. Nos casos de separação judicial de casais possuidores de animais de estimação, o animal nada mais era do que um bem a ser "partilhado", nos moldes do Direito Civil. Considerados como coisas passíveis de apropriação, os animais eram marcados por seus donos para que, em casos de fuga, não fossem apropriados por outras pessoas, já que, como bens, detinham valor comercial (RODRIGUES, 2012).

Com a Constituição Federal de 1988 e com o Código Civil de 2002, a questão que envolve homem e animal em seus Direitos subjetivos passou a ser percebida e 
com isso, os princípios da dignidade da pessoa humana e da afetividade, que se fazem extremamente presentes no Direito de família, concedem uma definição mais exata e extensa do que seria a formação de uma família, excluindo totalmente os preceitos biológicos e sociológicos impostos nos anos anteriores e criando um novo pensamento sobre a constituição de uma família multiespécie (RODRIGUES, 2012).

Contudo, como explanado alhures, já existe um Projeto de Lei aprovado pelo Senado Federal em 07 ago. 2019 que classifica o animal como sujeito de direito.

Ademais, é importante salientar que já é possível a efetivação do animal de estimação como parte da família de uma forma oficial, por meio de um documento disponível em Cartórios de Títulos e Documentos. A identipet é um registro de declaração de guarda de animais domésticos. Neste documento fica registrado o nome do tutor e também as informações como raça, cor, data de nascimento, nome e sobrenome do animal. Segundo a Tabeliã do $6^{\circ}$ Ofício de Registros de Títulos e Documentos e também idealizadora do projeto, Sônia Andrade, frisa-se a importância deste documento, pois visa exatamente a tutela e a proteção integral do animal. Registrando o animal, cria-se automaticamente um cadastro nacional aonde objetiva a proteger estes animais, além de facilitar o transporte e ajudar em disputas por guarda (BOM DIA RIO, 2017).

Analisando este paradigma, é necessário defender o Direito dos Animais para que alcance uma grande extensão e seja visível aos olhos de todos que ainda tem pensamentos retrógrados quanto a eles (animais), serem detentores de seus próprios Direitos. Ter nova postura e não negar defesa a esses seres que são desamparados juridicamente, podendo utilizar de meios adequados e corretos para os casos que envolverem relações de famílias multiespécie, cumprindo as obrigações do meio jurisdicional e preservando a integridade de cada ser que merece respeito (FERREIRA, 2014).

É por este motivo que os Tribunais, atualmente, estão sendo obrigado a usar a analogia para resolver conflitos envolvendo animais e humanos. Não há problemas em relação a isto pois a Lei de Introdução às Normas do Direito Brasileiro garante que em casos omissos a Lei, o uso da analogia é totalmente aceitável para decidir casos atípicos. Porém, para casos que envolvem animais de estimação, onde seus donos estão em conflito por conta da guarda compartilhada, a solução é superficial. O magistrado não pode fechar os olhos para algo que é novo perante a sociedade e 
precisa de soluções visíveis aos olhos de todos que buscam lutar para o direito dos seus animais que fazem parte do núcleo familiar (VALLE; BORGES, 2018).

Por se tratar de um assunto muito importante envolvendo guarda dos animais, existe uma grande dúvida, pois no ano de 2015, abordaram o assunto no Congresso brasileiro o projeto de Lei $n^{\circ} 1.365$, para regulamentação a guarda dos animais após separação judicial. Pretendia-se solucionar o conflito com audiência de conciliação e além de outros assuntos que poderiam ser discutidos antes de um processo judicial seguir em frente. Infelizmente o projeto mencionado acima não teve sucesso e é por este motivo que ainda as técnicas de analogia que são previstas no artigo $4^{\circ}$ da Lei de Introdução às Normas do Direito Brasileiro são usadas, pois não existem outros meios para resolver lides envolvendo animais domésticos e humanos em casos de separação judicial (VALLE; BORGES, 2018).

O Código Civil traz duas possibilidades de guarda, a compartilhada e a unilateral, ambas previstas nos casos de família pelo artigo 1.383 do Código Civil. A questão em pauta é justamente a guarda compartilhada, que impõem as duas partes responsáveis dividir direitos como questões alimentícias, educacionais e médicas, que seriam totalmente justificáveis, já que o casal tinha o animal de estimação juntamente e em comum acordo (VALLE; BORGES, 2018).

Não há distinção para um membro da família, sejam eles adotivos ou consanguíneos ou considerados por afeto, o que nos coloca sob um aspecto jurídico é a presença do vínculo em que há entre as partes. A ideia de núcleo familiar composto apenas por um homem e mulher que são obrigatoriamente cobrados a terem filhos afastou-se dos séculos novos (DIAS, 2019).

O conceito e a cultura mundial mudaram gradativamente. O conceito de família já não é mais o mesmo e a ideia de casamento, sexo e procriação já ficaram no passado. Hoje as famílias se destacam do conceito tradicionalista, abrindo alas assim, para as famílias multiespécie, baseadas na afetividade e vínculo entre homem e animal. É evidente que houveram mudanças claras nos paradigmas de família com os animais inclusos no núcleo familiar por opção do homem, gerando afeto e vínculos como de uma família tradicional. Sendo assim, o integrador e caracterizador da família precisa ser reconhecido como sujeito (DIAS, 2019).

Em vista disso, as relações das partes merecem continuar sendo ligadas pela afetividade, como já mencionado acima, pois o direito à convivência é próprio entre as 
partes conflitantes, sendo assim, tanto a guarda compartilhada como a guarda unilateral serão acordadas e o magistrado responsável pelo caso em tela estipulará as regras a serem seguidas (LÔBO, 2020).

Portanto, o mesmo deveria acontecer com a guarda compartilhada dos animais domésticos, já que vem sendo, de fato, um problema a ausência de Lei específica para ampará-los.

\subsection{DAS FORMAS DE PARENTESCO E DAS RELAÇÕES INTRÍNSECAS NO ÂMBITO FAMILIAR}

O Código Civil prevê os tipos de parentescos vigentes: afinidade significa que o parentesco é limitado aos ascendentes, descendentes e aos irmãos do cônjuge ou companheiro, não ultrapassando o $2^{\circ} \mathrm{grau}$, em linha colateral como o Código Civil nos traz em seu artigo 1.595, também ocorre o parentesco por afinidade em casamentos, uniões estáveis e adoções, e temos também a consanguinidade ou civil, o que define seu grau de parentesco é ter o mesmo sangue no tronco genealógico em comum, artigo 1.592. Em questões de Direito, nenhum sobrepõe o outro, sendo assim, as relações baseadas no afeto não devem ser menos importantes do que as consanguíneas porque a criação de um filho adotivo ou, neste caso, animal de estimação, surge de cada indivíduo por circunstancias alheias a imposição legal que o texto impõe (GONÇALVES, 2018).

Não faz sentido classificar as relações afetivas como menos importantes, já que a filiação biológica não é superior a consanguínea, uma vez que criar um filho afetivo surge também por vontade própria, alheia a imposição do que a Lei nos traz. O afeto cria os laços familiares, sendo este, disseminado dia a dia.

Para Fachin (2003), a verdade sociológica da filiação se constrói não somente na descendência, mas no comportamento de quem cuida e trata em público ou na intimidade do lar, com afeto paternal e que constitui um vínculo tão forte que ultrapassa os laços consanguíneos biológicos, compondo a base dos laços familiares.

Desse modo, questiona-se o motivo do não reconhecimento do direito dos animais, já que é uma situação que se encontra absolutamente formada e consolidada cada vez mais com o passar dos anos. O não reconhecimento desta nova realidade 
afronta severamente os princípios constitucionais e os Direitos Humanos (WOLF, 2019).

\title{
4 O ENQUADRAMENTO JURISPRUDENCIAL EM CASOS DE GUARDA COMPARTILHADA DOS ANIMAIS
}

Coadunado com a ideia explanada alhures, verifica-se o surgimento das novas famílias multiespécie. As questões envolvendo guarda de animais de estimação não demoraram a surgir nos Tribunais de todo o país.

Do estudo do ordenamento jurídico que trata especificamente sobre este assunto, observa-se que as jurisprudências atuais mostram um aumento significativo no número de casos semelhantes e também a forma com a qual os magistrados estão proferindo decisões, resguardando sempre o bem-estar do animal, considerando que as famílias multiespécie já são parte de uma nova realidade mundial.

O Recurso Especial que tramitou no Superior Tribunal de Justiça no ano de 2018, é um exemplo de que, cada vez mais, este novo conceito sobre família está presente na sociedade, vinda de uma possível Lei, já que tem sido tão comum casos com este assunto em pauta.

\begin{abstract}
RECURSO ESPECIAL No 1713167 SP 2017/0239804-9. DIREITO CIVIL. DISSOLUÇÃO DE UNIÃO ESTÁVEL. ANIMAL DE ESTIMAÇÃO. AQUISIĈ̃O NA CONSTÂNCIA DO RELACIONAMENTO. INTENSO AFETO DOS COMPANHEIROS PELO ANIMAL. DIREITO DE VISITAS. POSSIBILIDADE, A DEPENDER DO CASO CONCRETO (BRASIL, 2018).
\end{abstract}

Conforme é possível verificar acima, a parte autora ajuizou a ação pleiteando a regulamentação de visitas ao animal de estimação, já que as partes viveram em união estável durante vários anos e adquiriram o animal conjuntamente. A parte requerida alega que, com o passar dos anos, o laço afetivo com o cachorro tornou-se extremamente forte e que, apesar de ser a parte autora ser responsável pela totalidade do valor da compra do animal e dos gastos pertinentes ao cão, com a dissolução da união estável, o animal ficou com a mesma, porque até então teriam acordado em dividir as despesas e visitas ao animal. Apesar do acordo, o autor ficou proibido de visitar o animal, o que causou certa angustia e tristeza já que tinham grandes laços de afeto (BRASIL, 2018). 
O magistrado de primeira instancia, julgou o pedido do autor improcedente, motivando a decisão no sentido de que o animal é considerado um objeto para o Direito Civil Brasileiro e que, por este motivo, não pode ser comparado a um humano, de modo que integrar relações como pais e filhos, seria totalmente desconexo e aferiria os princípios jurídicos. Ao final, pontuou ainda que, como o animal é tratado como um objeto, a visitação seria relativamente desnecessária (BRASIL, 2018).

Isto posto, a parte autora apresentou recurso especial para que seus direitos em ver o animal fossem postos em pauta. O relator Luís Felipe Salomão, da $4^{a}$ Turma do TRF da $5^{\text {a }}$ Região, julgou o pedido parcialmente procedente nos seguintes termos: Primeiramente explanou que a discussão envolvendo entidade familiar e seus animais de estimação não deve ser afastada ou vista com menos importância, porque nos dias atuais é cada vez mais recorrentes casos que envolvem famílias multiespécie, deixando para traz o pensamento antigo de família tradicional.

Além do mais, estaria confrontando o mandamento constitucional previsto no artigo 225, § 1, inciso VII. Como bem o disse, o Código Civil realmente traz o animal de estimação como um bem, coisa, objeto. Afastando-a deles a qualidade de pessoa e também de possuírem qualquer personalidade jurídica. Porém, mais uma vez cita a grande importância que os animais têm aos seus donos e que sim, possuem sentimentos e vínculos que são bem diferentes de propriedade ou objeto. Reconhece ainda, que o ordenamento jurídico é falho em relação a isto, já que, não se trata de objetos que possuem valor comercial, mas sim, sentimental (BRASIL, 2018).

Novamente, o Relator cita que não é possível mais nos dias atuais desprezar tais ações como estas e fechar os olhos para tantos casos que ocorrem no Brasil. Ainda em sua fala, alude que os animais são seres dotados se senciência e que também devem ter seu bem-estar garantido (BRASIL, 2018).

Desse modo, é visto que os animais não podem ser mais classificados e tratados como objetos em casos de separação conjugal. O ser humano é um animal, ser vivo com capacidades de sentir, se locomover e se comunicar, que se assemelham muito aos animais, sendo assim, estes deveriam ser detentores de seus próprios direitos. A diferença que separa as espécies é a capacidade de lutar por seus direitos, de modo que os animais domésticos necessitam de uma figura que os represente, como a guarda de um animal que deve ser atribuída a alguém, como as crianças que 
necessitam de adultos para postular em juízo pedindo o Direito de guarda, alimentos (WOLF, 2019).

Por fim, o Relator fala como é de grande importância o Poder Judiciário encontrar uma correta solução para estes conflitos, de modo a resguardar os direitos fundamentais e não mais ignorar a Constituição. Afirma ainda, que o ordenamento jurídico não pode passar em cima e desprezar as relações multiespécie, ainda mais nos tempos atuais. Aqui, não estamos comparando o animal com uma criança, mas equipará-los de modo que mereçam uma Lei específica (BRASIL, 2018).

Indo além do problema da Legislação específica e de o animal ainda não ser tratado como um sujeito que merece ter seus direitos garantidos, os Tribunais também ficam confusos quanto em qual Vara julgar o processo. O Poder Judiciário, por falta de legislação para o referido tema, interpreta analogicamente o Código Civil aonde trata de Direito de Família, especificamente quando o tema é sobre guarda compartilhada, usa-se a fonte de Direito direcionada aos menores para resolver questões como divisão de despesas, regulamentação de visitas e alimentos. O fato é que a solução obtida é momentânea, sendo de fato necessário a instituição de Lei específica (BRASIL, 2018).

O julgado seguinte é a prova de que o embasamento no Código Civil é constante.

VOTO No 10559 AGRAVO DE INSTRUMENTO No 205211452.2018.8.26.0000 COMARCA: SÃO PAULO - $3^{\text {a }}$ VARA DA FAMÍLIA E SUCESSÕES JUIZ (A) DE $1^{\text {a }}$ INSTÂNCIA: RICARDO CUNHA DE PAUL AGRAVANTE: AGRAVADO: $7^{\text {a }}$ CÂMARA DE DIREITO PRIVADO AGRAVO DE INSTRUMENTO (SÃO PAULO. Tribunal de Justiça, 2018).

No julgamento deste agravo de instrumento que tramitou na $3^{\mathrm{a}}$ Vara da Família e Sucessões de São Paulo, a decisão foi contra ao pedido de posse compartilhada de um animal de estimação. O Relator José Rubens Queiroz Gomes citou o Código Civil de 2002, no qual os animais são tratados como objetos e que a relação entre animal e homem de fato não foi regulada por Lei (SÃO PAULO, 2018).

Porém, atualmente, o vínculo entre os animais domésticos e seus donos é tão extenso que uma pesquisa realizada pelo IBGE constatou que, atualmente, há mais cães de estimação do que crianças habitando os lares das famílias brasileiras (IBGE, 2015 apud INSTITUTO PET BRASIL, 2019). Diante desta lacuna na legislação 
brasileira para resolução dos conflitos envolvendo animais domésticos e as relações de afeto e de vínculo emocional para com seus tutores, a ideia de patrimônio valorativo não mais subsiste (SÃO PAULO, 2018).

Nestes casos, os juízes devem decidir conforme a Lei de Introdução às Normas de Direito Brasileiro, de modo que, caso a família constituída junto com o animal doméstico seja desfeita, mostra-se totalmente aceitável a analogia para resolução da lide, sendo, inclusive, a Vara da Família competente para julgar o feito (SÃO PAULO, 2018).

A ressignificação do que os animais domésticos representam para a sociedade dentro do núcleo familiar faz com que o Direito de Família norteie as discussões de guarda dos animais, por conta de selecionar o animal como sujeito e não mais como "coisa" (SÃO PAULO, 2018).

De fato, por se tratar de um tema relativamente novo, os Tribunais podem entender e se posicionar de diversas formas. A valer que toda esta situação gera insegurança jurídica para ambas as partes, até mesmo de quem está julgando, pois, as partes buscam uma forma correta de resolução destes conflitos e acabam se deparando com incertezas (VALLE; BORGES, 2018).

Este outro caso, envolvendo guarda compartilhada de um animal de estimação clarifica a ideia de que o tratamento dado pelo Relator ao caso assemelha-se muito a um processo envolvendo a guarda de criança.

AGRAVO DE INSTRUMENTO. AÇÃO DE RECONHECIMENTO E DISSOLUÇÃO DE UNIÃO ESTÁVEL. TUTELA DE URGÊNCIA. GUARDA DE ANIMAL DE ESTIMAÇÃO. INTERSECÇÕES ENTRE O DIREITO DAS COISAS E O DE FAMÍLIA (GOIÁS, 2019).

No caso, a parte autora entrou com o processo de dissolução de união estável, requerendo de imediato e com urgência a guarda do animal. O magistrado a quo indeferiu a liminar com o argumento de ausência de periculum in mora. A parte autora sustenta que a parte ré possui temperamentos violentos, que já existe medida protetiva para que não se aproxime da autora. Nestas condições, a guarda do animal merece ser adquirida apenas por uma das partes, já que em razão de posturas violentas, medidas protetivas e outros comportamentos fazem crer que o melhor para o cão é a guarda em favor da autora (GOIÁS, 2019). 
Diante destes fatos e em sede de agravo de instrumento, o desembargador Fausto Moreira Diniz decidiu que a ressignificação contemporânea do apreço dos animais de estimação dentro do núcleo familiar e a singularidade de afeto estabelecido transportam do Direito das Coisas para o de Família a dissolução judicial acerca de suas custódias. O desembargador levou em consideração as variáveis do litígio e concluiu que a autora possuía melhores condições para os cuidados necessários ao bem-estar do animal, concedendo a liminar para que permaneça com a guarda até a decisão final (GOIÁS, 2019).

Torna-se nítido, com a leitura dos referidos julgados, que grande parte dos julgadores vêm adotando a analogia ao Direito de Família para decidirem em casos que envolvem a guarda de animais de estimação. Demandas desta natureza fazem parte da rotina do poder judiciário, tornando imprescindível e extremamente necessária a elaboração de Lei específica para dirimir conflitos e tutelar os plenos direitos a estes seres (GOIÁS, 2019).

\section{CONSIDERAÇÕES FINAIS}

As famílias de hoje mudaram o conceito tradicionalista adotada nos tempos remotos. Não há como mascarar este fato já que cada vez mais torna-se recorrente ao passar dos dias. Sem Lei especifica para resolver estes conflitos, os operadores do Direito utilizam a analogia para estabelecer as questões envolvendo guarda compartilhada de animais domésticos.

Cada vez mais autores/pesquisadores estão tratando do tema deste artigo, tendo em vista a relevância do tema e a necessidade de contribuir para a valoração do animal como um ser senciente, merecedor de respeito e de direitos e garantias. Lutase, assim, para que seja estabelecido um novo ramo do direito. As jurisprudências apresentadas também demonstram a importância, a recorrência e o tratamento dado pelos Tribunais que estão analisando e buscando a melhor solução para todas as partes, inclusive o animal. Outros autores e, até mesmo projeto de Lei n ${ }^{\circ} 9.605$, de 12 de fevereiro de 1998, são capazes de assegurar que os direitos dos animais devem ser plenamente protegidos e garantidos, assegurando-lhes uma vida de qualidade, eis que demandam atenção plena de seus responsáveis, considerando que são seres com sentimentos e percepções. 
A família multiespécie, formada por humanos e animais vem se tornando cada vez mais recorrente no mundo inteiro, sendo uma decisão pessoal incluir estes seres em seus lares. É evidente e necessário a criação de Leis que possibilitem os animais e seus tutores a compartilharem guarda e visitas caso haja dissolução de união, como todas as outras criações de famílias conhecidas na realidade afetiva do mundo. Enquanto não existe uma nova Lei, por conta de o Poder Legislativo ignorar esses novos tempos de sociedade animal e homem, o Poder Judiciário tenta resolver como pode os conflitos envolvendo estas duas espécies em casos de guarda compartilhada, onde as duas partes requerem a possibilidade de compartilhar e continuar convivendo com o animal de estimação em casos de separação.

É necessário despertar o potencial na natureza humana e entender que não é só a figura do homem que merece proteção. Os animais são sujeitos ativos de direitos, seres capazes de sentir e merecem reivindicação de seus Direitos por parte de seus tutores.

Os seres humanos, e principalmente a área atuante do Direito, não podem fechar os olhos e ignorar a relevância do tema em pauta. A separação conjugal ocorre dia-a-dia em todo o território e a maioria das pessoas sofre com esta situação, inclusive quem está inserido nela, sejam crianças, pessoas próximas ao casal, família e os animais, que fazem parte do núcleo familiar de igual modo. Por ser, de fato, uma questão muito recente e ainda não regulada por Lei, certamente diversas famílias já tiveram suas relações abaladas e se viram frente a necessidade de recorrer ao judiciário para salvaguardar as relações de afeto para com o animal doméstico. 0 problema repousa no fato de nem o Poder Judiciário ser capaz de tutelar a plenitude deste direito constitucionalmente garantido e, com isso, necessária se faz a edição de uma norma específica, confirme os termos até aqui redigidos e que merecem a devida atenção. 


\section{REFERÊNCIAS}

AGUIAR, Jade Lagune Lanzieri. Direito dos animais sob os aspectos da guarda compartilhada e dano moral em caso de lesão do animal. 1. ed. Rio de Janeiro: Lumen Juris, 2018.

ATAIDE JUNIOR, Vicente de Paula. Introdução ao direito animal brasileiro. Revista Brasileira de Direito Animal, Salvador, v. 13, n. 3, p. 48-76, set./dez. 2018.

BOM DIA RIO. Idealizadora do projeto 'identipet' explica a importância de registrar animais. Rio de Janeiro, 21 mar. 2017. Disponível em:

https://g1.globo.com/rio-de-janeiro/noticia/idealizadora-do-projeto-identipet-explica-aimportancia-de-registrar-animais.ghtml. Acesso em: 29 maio 2020.

BRASIL. [Código Civil (2002)]. Lei n. 10.406, de 10 de janeiro de 2002. Institui o código civil. Disponível em: http://www.planalto.gov.br/ccivil_03/LEIS/2002/ L10406.htm. Acesso em: 15 jun. 2020.

BRASIL. [Constituição (1988)]. Constituição da República Federativa do Brasil, promulgada em 05 de Outubro de 1988. Disponível em: http://www.planalto.gov.br. Acesso em: 15 jun. 2020.

BRASIL. Senado Federal. Projeto de Lei da Câmara n. 27, de 2018. Brasília:

Senado Federal, [2018 ]. Disponível em: https://www25.senado.leg.br/web/atividade/ materias/-/materia/133167. Acesso em: 15 jun. 2020.

BRASIL. Superior Tribunal de Justiça. Recurso Especial n¹713167- SP

2017/0239804-9. Relator: Min. Luis Felipe Salomão. 19 jun. 2018. Disponível em: https://ww2.stj.jus.br/processo/revista/inteiroteor/?num_registro=201702398049\&dt_ publicacao=09/10/2018. Acesso em: 12 maio 2020 .

DIAS, Maria Berenice. Manual do direito das famílias. 13. ed. São Paulo: Juspodivm, 2019.

FACHIN, Luiz Edson. Comentários ao novo código civil: do direito de família; do direito pessoal; das relações de parentesco. 1. ed. Rio de Janeiro: Forense, 2003. v. 18.

FERREIRA, Ana Conceição Barbuda Sanches Guimarães. A proteção aos animais e o direito. 1. ed. Curitiba: Juruá Ed., 2014.

FRANCIONE, Gary Lawrence. Introdução ao direito dos animais. 1.ed. Campinas: Unicamp, 2015.

GOIÁS. Tribunal de Justiça. $6^{\text {a }}$ Câmara Cível. Agravo de Instrumento ${ }^{\circ}$

5450918.02.2018.8.09.0000. Relator: Des. Fausto Moreira Diniz. Goiânia, 03 abr. 2019. Disponível em: https://projudi.tjgo.jus.br/BuscaArquivoPublico?PaginaAtual= 
6\&Id_MovimentacaoArquivo=93249918\&hash $=312585801377991020052541756521$ 283780473\&CodigoVerificacao=true. Acesso em: 12 maio 2020.

GONÇALVES, Carlos Roberto. Direito civil: direito de família. 22.ed. São Paulo: Saraiva, 2018. E-Book

IBAMA (Instituto Brasileiro do Meio Ambiente). Portaria IBAMA nº 93 / 1998, de 07 de julho 1998: (Importação e Exportação Fauna Silvestre). Brasília: IBAMA, 1998. Disponível em: http://www.sema.df.gov.br/wp-conteudo/uploads/2017/09/PortariaIBAMA-n\%C2\%BA-93-de-1998.pdf. Acesso em: 27 maio 2020.

INSTITUTO PET BRASIL. Censo Pet: 139,3 milhões de animais de estimação no Brasil. São Paulo: Instituto Pet Brasil, 12 jun. 2019. Disponível em:

http://institutopetbrasil.com/imprensa/censo-pet-1393-milhoes-de-animais-deestimacao-no-brasil/. Acesso em: 12 maio 2020.

LÔBO, Paulo. Direito civil: famílias. 10.ed. São Paulo: Saraiva, 2020.

LOW, Philip et al. Declaração sobre a consciência de Cambridge. In: CONFERÊNCIA MEMORIAL FRANCIS CRICK SOBRE CONSCIÊNCIA EM ANIMAIS HUMANOS E NÃO HUMANOS. Cambridge, Reino Unido: Churchill College da Universidade de Cambridge, 7 jul. 2012. Disponível em:

https://www.animal-ethics.org/declaracao-consciencia-cambridge/. Acesso em: 03 maio 2020.

RODRIGUES, Danielle Tetu. Direito e os animais: uma abordagem ética, filosófica e normativa. 2. ed. Curitiba: Juruá Ed., 2012.

SÃO PAULO. Tribunal de Justiça. $3^{a}$ Vara da Família e Sucessões. Agravo de Instrumento $n^{\circ}$ 2052114-52.2018.8.26.000. Relator: José Rubens Queiroz Gomes. São Paulo, 23 mar. 2018. Disponível em: https://cnbmg.org.br/clipping-migalhasvara-de-familia-tem-competencia-para-decidir-guarda-compartilhada-de-animaisafirma-tjsp/ Acesso em: 12 maio 2020.

TRENNEPOHL, Terence Dornelles. Manual de direito ambiental. São Paulo: Saraiva, 2019. E-book.

UNESCO. Declaração Universal dos Direitos dos Animais. Bruxelas, Bélgica, 27 jan. 1978. Disponível em: http://www.urca.br/ceua/arquivos/Os\%20direitos \%20dos\%20animais\%20UNESCO.pdf. Acesso em: 12 maio 2020.

VALLE, Ana Carolina Neves Amaral do; BORGES, Izabela Ferreira. A guarda dos animas de estimação no divórcio. Academia Brasileira do Direito Civil, v. 3, n. 2, 2018. Disponível em: https://abdc.emnuvens.com.br/abdc/article/view/22/18. Acesso em: 12 abr. 2020.

VIEGAS, Cláudia Mara de Almeida Rabelo; RABELO, Cesar Leandro de Almeida; PAMPLONA FILHO, Rodolfo. Dissolução da família multiespécie. Direito UNIFACS: debate virtual, n. 236, fev. 2020. 
WOLF, Karen Emília Antoniazzi. Proteção jurídica do animal não humano. 1. ed. Rio de Janeiro: Lumen Juris, 2019.

Artigo recebido em: 17/08/2020

Artigo aceito em: 07/10/2020

Artigo publicado em: 27/09/2020 